\title{
COMPETITIVIDADE DAS EXPORTAÇÕES BRASILEIRAS DE MAMÃO, 1995 A 2008'
}

\author{
Fernanda Aparecida Silva ${ }^{2}$ \\ Marília F. Maciel Gomes ${ }^{3}$ \\ Daniel Arruda Coronel ${ }^{4}$ \\ Marco Túlio M. Gomes ${ }^{5}$
}

\begin{abstract}
Resumo: O presente trabalho tem por objetivo avaliar o comportamento das exportações brasileiras de mamão, bem como analisar se as exportações do produto estão sendo orientadas para a União Europeia e o Tratado Americano de Livre Comércio (Nafta). São utilizados na análise o período de 1995 a 2008 e sua divisão em dois subperíodos: 1995/1998 a 1999/2001 e 1999/2001 a 2002/2008. O procedimento de análise baseia-se no modelo Constant-Market-Share, no Índice de Orientação Regional (IOR) e no Índice de Cobertura (IC). Os resultados encontrados mostram que o efeito que mais contribuiu para o desempenho das exportações brasileiras de mamão, no período I, foi a competitividade, impulsionada pela estabilidade da economia, desvalorização cambial, variáveis internas e programas do governo. Já no período II, o crescimento do comércio mundial foi o maior representante, seguido pelo efeito destino das exportações. A análise do Índice de Orientação Regional indicou que as exportações de mamão estão mais orientadas para a União Europeia do que para o Nafta. Por fim, por meio do Índice de Cobertura, ficou constatado que o bloco norte-americano emitiu um número maior de notificações ao mamão brasileiro em relação ao bloco europeu.
\end{abstract}

Palavras-chave: Mamão, competitividade, comércio internacional.

\footnotetext{
Recebido em: 25/10/11. Aceito em: 2/3/2012.

2 Graduanda do curso Gestão do Agronegócio pela Universidade Federal de Viçosa - UFV, Bolsista PIBIC/ CNPq. E-mail: fernanda.aparecida@ufv.br

3 Professora Associada do Departamento de Economia Rural, Universidade Federal de Viçosa - UFV. E-mail:mfmgomes@ufv.br

4 Professor Adjunto do Mestrado em Administração, Universidade Federal de Santa Maria - UFSM. E-mail: daniel.coronel@ufv.br

5 Doutorando em Economia Aplicada, Universidade Federal de Viçosa - UFV
} 


\begin{abstract}
The aim of this work is to assess Brazilian papaya exports as well as to analyze if these exports are being oriented for European Union and North American Free Trade Agreement (NAFTA). The period of analysis was between 1995 and 2008 subdivided in 1995/1998, 1999/2001, 1999/2001, 2002/2008. The analysis procedure is based in the model Constant-Market-Share, in the Regional Orientation Index (ROI) and in the Index Covering (IC). The results found show that the competitiveness driven by the stability of economy, exchange devaluation, internal variables and government programs contributed more for the growth of Brazilian papaya exports in period I. In period II, it was the growth of world trade and the destiny of exports. The analysis of Regional Orientation Index showed that the papaya exports are more oriented for European Union than North American Free Trade Agreement. By way of the Index Covering, it was found that the North Americans gave more notifications for Brazilian Papaya than the Europeans.
\end{abstract}

Keywords: papaya, competitiveness, world trade.

\title{
1. Introdução
}

A fruticultura é um dos setores da economia brasileira de grande destaque, pois além de apresentar evolução contínua visando a atender a um mercado interno em crescimento, tem buscado melhor acesso ao mercado mundial. A cadeia produtiva de frutas no Brasil abrange cerca de 4,3 milhões de hectares, gerando, aproximadamente, seis milhões de empregos diretos, ou seja, $36 \%$ do total da mão de obra agrícola ocupada no país (BRAZILIAN FRUIT, 2010).

Esse setor demanda mão de obra intensiva e qualificada, utilizada em operações manuais como capina, pulverização, combate a pragas e colheita. A importância da fruticultura na geração de empregos pode ser ressaltada pelo fato de cada 10.000 dólares investidos na atividade gerarem três empregos diretos e permanentes e dois indiretos (BRAZILIAN FRUIT, 2010).

A produção frutícola brasileira está voltada para frutas tropicais, subtropicais e temperadas, e isto se deve à sua extensão territorial, posição geográfica, solo e condições climáticas favoráveis. De acordo com o 
Fernanda Aparecida Silva, Marilia F. Maciel Gomes,

Daniel Arruda Coronel \& Marco Túlio M. Gomes

Instituto Brasileiro de Frutas - I (2010), o Brasil é o terceiro maior produtor de frutas do mundo. Sua produção superou 43 milhões de toneladas em 2008, representando 5\% da produção mundial. Com esse total, o país fica atrás apenas da China e da Índia, que produziram, no mesmo ano, 175 e 57 milhões de toneladas, respectivamente. Aproximadamente 53\% da produção brasileira é destinada ao mercado de frutas processadas e $47 \%$ ao mercado de frutas frescas.

O mamão é uma das frutas de grande representatividade na produção e exportação no País. Segundo dados do Instituto Brasileiro de Geografia e Estatística - IBGE (2010), a produção nacional de mamão foi, em 2008, de 1.890.286 toneladas, e os maiores produtores brasileiros estavam localizados na Bahia (902.525 toneladas), Espírito Santo (630.124 toneladas) e Rio Grande do Norte (106.064 toneladas). Entre esses estados, o Espírito Santo, em 1998, foi o primeiro habilitado a exportar esta fruta para os Estados Unidos. Já em 2005, os estados da Bahia e do Rio Grande do Norte também foram autorizados a exportar o mamão para o mercado norte-americano.

As principais regiões que importaram o mamão brasileiro, em 2008, foram a União Europeia, com 20.356 toneladas, e a Nafta, com 4.546 toneladas, de acordo com o Ministério do Desenvolvimento, Indústria e Comércio MIDIC/SECEX (2010).

As exportações de mamão são importantes na geração de receita para a economia interna, já que é uma fruta tropical brasileira importante para o comércio internacional do setor. Em 1995, as exportações de mamão foram da ordem de US\$ 4,02 milhões. A partir do ano de 1999, houve aumento significativo no valor exportado, passando para US\$13,57 milhões. Nos anos seguintes, o valor exportado continuou aumentando, chegando em 2008 a US\$38,61 milhões (SECEX, 2010).

A parcela de participação do Brasil no mercado internacional de mamão tem sido crescente, notadamente, no período que este estudo abarca (Tabela 1). Em se tratando do período 1995/1998 (média dos valores 
das exportações dos quatro anos), o Brasil foi responsável por $8 \%$ das exportações mundiais de mamão. No período de 1999/2001, o país participou com $15 \%$ das exportações mundiais desse produto, e de 2002 a 2008 , com participação ainda crescente, foi responsável por $20 \%$ das exportações.

Tabela 1 - Exportações mundiais e brasileiras de mamão, 1995 a 2008, em 1000 US\$

\begin{tabular}{l|ccc}
\hline & $\mathbf{1 9 9 5 / 1 9 9 8}$ & $\mathbf{1 9 9 9 / 2 0 0 1}$ & $\mathbf{2 0 0 2 / 2 0 0 8}$ \\
\hline Exportações Mundiais & 321788 & 331318 & 1065734 \\
Exportações Brasileiras & 25475 & 49777 & 211091 \\
Market Share & $8 \%$ & $15 \%$ & $20 \%$ \\
\hline
\end{tabular}

Fonte: Elaborado pelos autores.

A exportação de mamão nacional, por outro lado, enfrenta barreiras tarifárias ${ }^{6}$, e é fortemente afetada por barreiras não-tarifárias ${ }^{7}$, principalmente as de caráter técnico e fitossanitário.

Em face do crescimento das exportações de mamão e da significativa representatividade do país na exportação mundial da fruta (Tabela 1), torna-se relevante empreender pesquisas que visem a analisar a competitividade, a dinâmica da produção e das exportações nacionais deste produto. Assim, o presente trabalho tem por objetivo avaliar o comportamento das exportações brasileiras de mamão por meio dos efeitos comércio mundial, destino das exportações e competitividade, entre 1995 e 2008, período pós-implantação do plano real, de elevação das exportações agroindustriais e anos recentes das exportações de mamão nacional. Pretende-se também analisar se as exportações do produto estão sendo orientadas para a União Europeia e para o Tratado Americano de Livre Comércio - Nafta.

Impostos cobrados quando um bem é importado.

Cotas, restrições voluntárias às exportações, subsídios às exportações, barreiras técnicas, ecológicas, burocráticas e sanitárias. 
Seguindo esta temática, este trabalho está dividido em quatro seções, além da introdução. Na segunda seção, é apresentado o referencial teórico do trabalho; na terceira seção, são expostas a metodologia e a fonte de dados; na quarta seção, os resultados são analisados e discutidos e, finalmente, expostas as principais conclusões.

\section{Referencial Teórico}

As relações econômicas, políticas e sociais entre os países se intensificaram como consequência do processo de globalização e, neste sentido, torna-se fundamental a compreensão das relações competitivas entre os países no comércio internacional.

A primeira teoria que buscou explicar as interações entre os países no comércio internacional foi a Teoria das Vantagens Absolutas proposta por Adam Smith. De acordo com essa teoria, as nações deveriam especializar-se na produção da commodity que produzissem com maior vantagem absoluta e trocar parte de sua produção pela commodity que produzissem com menor desvantagem absoluta (SMITH, 1937).

Essa Teoria não explicava totalmente as bases do comércio, visto que se uma nação não apresentasse nenhuma vantagem absoluta, não poderia participar do comércio. David Ricardo (1963) tenta corrigir estas falhas da teoria de Adam Smith ao expor, no The principles of political economy and taxation, que mesmo uma nação apresentando desvantagem absoluta na produção de ambas as commodities, ainda assim haveria uma possibilidade de comércio, desde que a nação se especializasse na produção de sua commodity de menor desvantagem absoluta.

Contudo, essas teorias ainda não explicavam os efeitos do comércio internacional, visto que passavam a idéia de que o comércio sempre era benéfico aos participantes. Então, com o objetivo de explicar a distribuição de renda entre os proprietários dos fatores produtivos, surge a Teoria das Proporções dos Fatores proposta por Eli Hescksler e Berthil Ohlin - 
Teorema de Heckscher-Ohlin. Esse teorema pode ser resumido da seguinte maneira: cada nação exportará a commodity intensiva em seu fator abundante de produção e importará aquela que exige a utilização do seu fator escasso e caro de produção (WILLIANSON, 1998).

Segundo Salvatore (1999), o Teorema de Hecksher-Ohlin baseia-se nos seguintes pressupostos: existem duas nações e dois fatores de produção (capital e trabalho); a tecnologia está disponível no mundo; a commodity x é mão de obra intensiva e a commodity y é capital intensivo, em ambas as nações; ambas as commodities são produzidas sob retornos constantes de escala; existe especialização incompleta na produção de ambas as nações; cada país compartilha padrões de preferências idênticos e homotéticos; existe concorrência perfeita em ambas as nações; há mobilidade perfeita dos fatores de produção em ambas as nações, contudo ausência de mobilidade internacional dos fatores; ausência de custos, tarifas e obstáculos ao comércio; todos os recursos são plenamente ocupados em ambas as nações; e o comércio internacional, entre ambas as nações, encontra-se em equilíbrio.

Os pressupostos formulados por Heckscher-Ohlin tiveram grande importância e influência nas Teorias de comércio internacional subsequentes. A partir dela, sugiram outras, merecendo destaque a Teoria de Linder, o Ciclo do Produto, desenvolvido por Vernon, e o Modelo de Defasagem Tecnológica, postulado por Posner (SALVATORE, 1999).

As teorias para a compreensão da competividade no comércio internacional tiveram uma nova conotação a partir da Teoria das Vantagens Comparativas Reveladas propostas por Bela Balassa, em 1965. Essa teoria tem como objetivo identificar para quais commodities um país apresenta Vantagem Comparativa na Produção e na Exportação. Nessa teoria, a Vantagem Comparativa é considerada revelada, pois sua quantificação se baseia em dados ex-post, ou seja, em dados pós-comércio (BALASSA, 1965).

Contudo, a teoria apresenta algumas limitações, pois, ao analisar as Vantagens Comparativas Reveladas, não considera questões relacionadas 
ao protecionismo tais como barreiras tarifárias e não-tarifárias, mudanças cambiais, entre outras variáveis. Por isso, tornam-se fundamentais as teorias da competividade que levam em conta tais variáveis (HIDALGO, 1998).

As Teorias de comércio em geral possuem explicações dúbias para definir competividade, visto que, para determinadas correntes, têm sido vistas como fenômenos macroeconômicos e, para outras, como dotações de fatores (PORTER, 1998).

Com a intensificação do processo de globalização, da inovação tecnológica e da dotação de fatores comparáveis, enfraqueceram-se as Vantagens Comparativas que determinadas nações tinham, visto que as indústrias compensam os fatores escassos por meio de novos processos (PORTER, 1999).

As Vantagens Absolutas e Comparativas são importantes para um país, contudo não se pode atribuir exclusivamente às Vantagens Comparativas, em termos de custos de fatores, o sucesso da indústria, visto que as vantagens de fatores se tornam com frequência passageiras, e a Vantagem Competitiva, que repousa sobre os custos de fatores, é vulnerável (PORTER, 1999).

Para Porter (1998), as empresas precisam ter vantangens competitivas relacionadas a menores custos de produção, produtos diferenciados, bem como manter a vantagem conquistada por meio de uma vantagem competitiva mais sofisticada. Ainda segundo o autor, a construção de um novo paradigma para explicar a competividade no comércio internacional deve ter como base a economia de escala, a diferenciação de produtos e cada vez mais o aperfeiçoamento da tecnologia.

Por mais importante que tenha sido a contibuição de Porter à Teoria do Comércio Internacional no que tange a políticas nacionais de competividade, ainda assim se faz pertinente aperfeiçoar os estudos que têm como temática a competitividade no comércio internacional, principalmente no contexto da globalização e da regionalização das economias. 


\section{Metodologia}

\subsection{Referencial analítico}

O modelo analítico utilizado no presente estudo visando a atender aos objetivos propostos está balizado no modelo Constant-Market-Share, no Î́ndice de Orientação Regional (IOR) e no Índice de Cobertura (IC).

\subsubsection{Modelo Constant-Market-Share}

Os estudos baseados nos modelos Constant-Market-Share têm por objetivo avaliar a participação de um país ou região no fluxo mundial ou regional de comércio e analisar as tendências das exportações e/ou importações de acordo com seus determinantes (CORONEL;MACHADO;CARVALHO, 2009).

No modelo, cada país ou bloco mantém constante sua parcela no comércio mundial. Caso haja alteração nessa parcela, ela deve estar implícita no modelo e sua efetiva performance é atribuída à competitividade. Neste caso, a taxa de crescimento das exportações é decomposta em quatro efeitos: crescimento do comércio mundial, composição da pauta de exportações, destino das exportações e competitividade.

O Constant-Market-Share permite determinar o peso de cada um desses efeitos nas exportações e mostra a extensão para a qual elas se direcionam para mercadorias e/ou mercados com maior potencial de expansão. Segundo Carvalho (1995), apesar de o método ter um caráter retrospectivo, há possibilidade de se fazer inferências sobre o direcionamento do setor exportador para mercados mais vantajosos e sobre a concentração em mercadorias com perspectivas mais dinâmicas, pressupondo a continuidade das tendências observadas nesses mercados.

A equação completa do modelo que leva em consideração todos os efeitos, anteriormente mencionados, é apresentada a seguir: 
Fernanda Aparecida Silva, Marília F. Maciel Gomes,

Daniel Arruda Coronel \& Marco Túlio M. Gomes

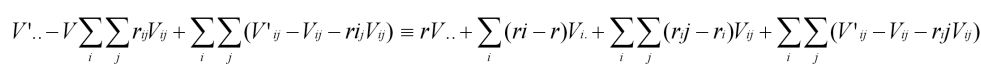
(a) (b)
(c)
(d)

em que:

Vij = valor das exportações da mercadoria i para o país j, no período 1;

V'ij = valor das exportações da mercadoria i para o país j, no período 2;

rij $=$ incremento percentual das exportações mundiais da mercadoria $\mathrm{i}$ para o país j do período 1 para o período 2 ;

$\mathrm{V}=$ valor total das exportações do país j; e

$\mathrm{r}=$ mudança percentual nas exportações mundiais do período (I) para o período (II).

A expressão (1) permite decompor a taxa de crescimento das exportações do país A em quatro efeitos:

$\mathrm{O}$ efeito crescimento do comércio mundial (a), $\mathrm{rV}$, mostra se as exportações do país aumentam quando a taxa de crescimento do comércio mundial também se eleva, ou seja, a partir desse efeito é possível verificar se o crescimento das exportações ocorre devido ao crescimento mundial das exportações.

O efeito composição da pauta (b), $\sum_{i}\left(r_{i}-r\right) V_{i .}$, indica que, se as exportações mundiais do produto $(i)$ aumentarem mais que a média mundial para todas as mercadorias exportadas, $\left(r_{i}-r\right)$ é positivo. $\mathrm{O}$ resultado tornará forte esse efeito se $V_{i}$ for relativamente grande, ou seja, o efeito composição da pauta será positivo se as exportações do país A estiverem concentradas no produto de maior expansão ou quando a taxa de crescimento for superior à média mundial. 
O efeito destino das exportações (c), $\sum_{i} \sum_{j}\left(r_{i j}-r\right) V_{i j}$, será positivo se o país A tiver concentrado suas exportações em mercados que experimentaram maior dinamismo no período analisado e negativo se concentrado em regiões mais estagnadas.

O efeito competitividade (d), $\sum_{i} \sum_{j}\left(V^{\prime} i j-V_{i j}-r_{i j} V_{i j}\right)$, significa que uma economia é competitiva na produção de determinada commodity quando consegue pelo menos igualar-se aos padrões de eficiência vigentes no resto do mundo quanto à utilização de recursos e à qualidade do bem. A diferença entre o crescimento das exportações verificadas pelo modelo CMS e o crescimento efetivo das exportações é atribuída ao efeito competitividade. A medida deste efeito está relacionada a mudanças nos preços relativos $\frac{p_{1}}{p_{2}}$. Assim, quando um país deixa de manter sua parcela no mercado mundial, o termo competitividade torna-se negativo e indica o fracasso do país em manter sua parcela no mercado mundial como também que os preços estão aumentando para o país em questão em proporção maior que seus competidores, ou seja, os importadores tendem a substituir o consumo das commodities cujos preços se elevaram pelo consumo daquelas com preços menores em termos relativos.

\subsection{2. Índice de Orientação Regional}

Para medir o grau de penetração do mamão brasileiro ou o seu peso relativo no mercado dos blocos União Europeia e Nafta, os principais importadores do produto em questão, utiliza-se o Índice de Orientação Regional (IOR). Esse índice é expresso da seguinte forma:

$$
I O R=\left(X_{r j} / X_{t r}\right) /\left(X_{o j} / X_{t o}\right)
$$


em que $X_{r j}$ é o valor das exportações brasileiras de mamão intrabloco; $X_{t r}$, o valor total das exportações brasileiras intrabloco; $X_{o j}$, o valor das exportações brasileiras de mamão extrabloco; $X_{\text {to }}$, o valor total das exportações brasileiras extrabloco; $r$, as exportações brasileiras intrabloco; $\mathrm{o}$, as exportações brasileiras extrabloco; e j, o produto mamão.

Esse índice se encontra em um intervalo de zero a infinito, no qual a unidade indica que há uma tendência em exportar o produto a membros e a não membros. Valores crescentes observados ao longo do tempo indicam tendência em exportar mais para dentro do bloco (YEATS, 1997).

\subsection{3. Índice de Cobertura}

O Índice de Frequência (IF) e o Índice de Cobertura (IC) são utilizados para fazer análise sobre o inventário das notificações aos Acordos SPS e TBT. O cálculo desses índices permite estimar o montante do comércio sujeito às barreiras não-tarifárias ou sua frequência de aplicação sobre setores específicos ou países.

Para identificar as principais medidas regulatórias que os maiores importadores impõem ao mamão produzido no Brasil, devem-se coletar todas as notificações SPS e TBT no período analisado. Essas notificações mostram a quais condições sanitárias e fitossanitárias a fruta deve obedecer, assim como a quais regulamentos técnicos e procedimentos de avaliação, em conformidade com padrões preestabelecidos.

Destaca-se que neste trabalho foi estimado somente o Índice de Cobertura, uma vez que no cálculo do Índice de Frequência (IF) é requerido um fluxo de $m$ produtos. Assim, no caso em estudo, em que se analisa apenas o mamão, seu valor é sempre a unidade.

O Índice de Cobertura (IC), calculado pela razão do somatório do valor das exportações de cada produto sujeito à notificação, em determinada categoria de produtos do sistema harmonizado $(\mathrm{SH})$, e do valor total das exportações daquele grupo (SH), é descrito pela expressão a seguir: 
$I C_{i j}=\left[\frac{\sum_{i=1}^{m}\left(V_{j m} * N_{j m}\right)}{\sum_{i=1}^{m}\left(V_{j m}\right)}\right] * 100$

em que $I C_{i j}$ é o coeficiente de cobertura das BNTs incidentes sobre o grupo i (mamão) composto de $\mathrm{m}$ linhas tarifárias e impostas pelo país $\mathrm{j}$ (cada um dos mercados de destino); $V_{j m}$, o valor das importações do país j dos produtos m, pertencentes ao grupo i; $N_{j m}=0$, se não houver incidência de alguma BNT sobre o produto $\mathrm{m}$; e $\mathrm{Njm}=1$, se houver incidência de BNT sobre o produto m. De acordo com Bellonia (2006), este índice permite estimar o montante de comércio sujeito às barreiras.

Quanto mais elevado for o IC, pressupõe-se, em geral, maior restrição ao comércio. Entretanto, deve-se ressaltar que esse índice não fornece nenhuma indicação sobre os efeitos que as notificações possam ter sobre as decisões de preço e quantidade dos exportadores.

\subsection{Operacionalização e Fonte de dados}

Os dados referentes ao valor das exportações brasileiras de mamão intrabloco/países e extrabloco/países, valor total das exportações brasileiras intrabloco/países e extrabloco/países, usados para calcular o IOR, foram obtidos no sistema de análise das Informações de Comércio Exterior - Aliceweb - da Secretária de Comércio Exterior (Secex), órgão vinculado ao Ministério do Desenvolvimento, Indústria e Comércio Exterior (MDIC).

Para o modelo Constant-Market-Share, os dados foram coletados no Sistema Aliceweb, Food Agriculture Organization (FAO) e no Ministério da Agricultura da Pecuária e do Abastecimento (Mapa). Esses dados dizem respeito ao volume de mamão exportado pelo Brasil para a União Europeia e Nafta, nossos maiores importadores. 
No modelo Constant Market Share, é realizada uma análise para dois subperíodos: 1995/1998 a 1999/2001, período I - pós-implantação do Plano Real, período de elevação das exportações agroindustriais, e 1999/2001 a 2002/2008, período II - período de elevação das exportações agroindustriais brasileiras e anos recentes das exportações de mamão nacional.

As informações sobre as notificações impostas pelos principais importadores foram coletadas no site da OMC (TWO, 2011) para os códigos $08^{8}$ (edible fruit and nuts; peel of citrus fruit or melon), 0807 (Melons, including watermelons and papaws - melões) e 080720 (Papaws, papayas).

\section{Análise e discussão dos resultados}

\subsection{Decomposição das fontes de crescimento das exportações de mamão no período I, 1995/1998 a 1999/2001 e no período II, $1999 / 2001$ a 2002/2008}

Analisando as exportações brasileiras de mamão do período I, verificase que o efeito competitividade foi o que mais contribuiu para o aumento das exportações nacionais, como mostra a Tabela 2, com 79,29\%. O efeito crescimento do comércio mundial (28,63\%) também influenciou no aumento das exportações brasileiras, já o efeito destino das exportações foi negativo, ou seja, se a participação do Brasil no comércio internacional de mamão fosse mantida constante, as exportações teriam sido superiores na ausência desse efeito. Resultado similar foi encontrado por Vitti (2009), que utilizou o modelo Constant Market Share para analisar as fontes de crescimento das exportações de frutas selecionadas, no período de 1989 a 2006, tendo observado que o principal responsável pelo desempenho das exportações de mamão no primeiro período (1989/90/91 a 1997/98/ 99) foi o crescimento do mercado e a competitividade, sendo o último efeito o mais representativo.

\footnotetext{
Classificação da OMC para os produtos para os quais são emitidas as notificações, de acordo com o Sistema Harmonizado (SH).
} 
Tabela 2 - Resultados Constant Market Share mamão, 1995 a 2008

\begin{tabular}{lcc}
\hline & $\mathbf{1 9 9 5 / 1 9 9 8}$ a 1999/2001 (\%) & $\mathbf{1 9 9 9 / 2 0 0 1}$ a 2002/2008 (\%) \\
\hline Crescimento do & 28,63 & 96,75 \\
Comércio Mundial & $-7,91$ & 18,7 \\
Destino das Exportações & 79,29 & $-15,45$ \\
Competitividade & &
\end{tabular}

Fonte: Elaborado pelos autores.

O efeito competitividade é composto por algumas variáveis que podem exercer influência sobre o aumento das exportações, como, por exemplo, a estabilidade da economia, que, após a implantação do Plano Real, mostrou baixas taxas de inflação. Segundo Pinheiro (1999), o Plano Real objetivava, além de criar condições macroeconômicas favoráveis à estabilização dos preços, alinhar os preços relativos mais importantes da economia, ou seja, controlar o preço, taxa de juros, câmbio e renda.

A Lei Kandir, de 1996, ao isentar o Imposto sobre Circulação de Mercadorias e Serviços (ICMS) para produtos primários e semiindustrializados, estimulou as exportações de mamão, contribuindo positivamente para o efeito competitividade.

Ademais, vale ressaltar que a competitividade do mamão e demais produtos do agronegócio foi favorecida pela desvalorização cambial em 1999, possibilitando maior participação no mercado mundial. Essa afirmativa também foi corroborada por Coronel et al. (2008), que utilizaram o modelo Constant Market Share para analisar as exportações brasileiras do complexo soja, de 1995 a 2004.

Variáveis internas também estão relacionadas ao efeito competitividade, como fatores climáticos, terra abundante e a criação do Programa de Modernização da Frota de Tratores Agrícolas e Implementos Associados e Colheitadeiras (Moderfrota) em 2000, que teve por objetivo modernizar o maquinário utilizado pelo agronegócio e obter maiores investimentos em pesquisa e desenvolvimento. Destaca-se também a Cédula do Produtor Rural (CPR), que, de acordo com Moreira (1998), o produtor vende a "termo" sua produção, recebe o valor da venda no ato da 
formalização do negócio e se compromete a entregar o produto vendido em quantidade, qualidade e em local e data estipulados. Portanto, a CPR visa a fornecer liquidez ao produtor, bem como assegurar os preços.

A competitividade do mamão brasileiro também é favorecida pelo desenvolvimento da infraestrutura em regiões exportadoras do produto, como o Rio Grande do Norte, $3^{\circ}$ estado exportador de mamão do país. Nesse estado, o governo tem desenvolvido várias ações para garantir a competitividade aos produtos da fruticultura, como a construção da Estrada do Melão para facilitar o escoamento da produção e reduzir o desperdício de frutas na região.

O segundo fator em termos de relevância de impacto nas exportações de mamão foi o crescimento do comércio mundial, contribuindo para o aumento das exportações desse produto. Esse efeito já poderia ser observado dado o grande crescimento das exportações mundiais de mamão nesse período (Tabela 1).

Por fim, o efeito destino das exportações, que foi negativo $(-7,915)$, mostra que as exportações brasileiras de mamão não foram destinadas a mercados muito dinâmicos. Isso significa dizer que o país exportou para mercados menos dinâmicos (em termos de importações de mamão) do que a média mundial.

Os resultados do modelo Constant Market Share obtidos para o período II (1999/2001 a 2002/2008), apresentados na Tabela 2, indicam que o fator de maior importância na explicação das altas taxas de crescimento das exportações brasileiras de mamão foi o crescimento do comércio mundial e o destino das exportações. Os resultados corroboram aqueles obtidos no estudo feito por Vitti (2009) acerca da competitividade das exportações de frutas selecionas entre 1989 e 2006, tendo sido verificado que, para o segundo período (1997/98/99 a 2004/05/06), os efeitos destino das exportações e crescimento de mercado foram os principais determinantes do desempenho das exportações de mamão. 
O efeito destino das exportações contribuiu com $18,7 \%$ para a elevação das exportações de mamão, embora seja menos expressivo que o efeito crescimento do comércio mundial. Isso significa dizer que o Brasil exportou este produto para mercados mais dinâmicos, diferentemente da situação analisada no período I.

Por meio da Tabela 2 é possível observar que o efeito competitividade, expressivo no primeiro período, torna-se negativo no segundo. Este resultado evidencia que nos últimos anos a exportação brasileira de mamão está mais dependente do crescimento do comércio mundial. Além disso, é interessante ressaltar que a partir de 2004 o preço FOB (preço ofertado cobrindo todas as despesas e riscos do produto, sem a contratação do frete internacional) do mamão brasileiro aumentou, podendo este ser um dos fatores que resultaram no valor negativo do referido efeito. $\mathrm{O}$ aumento nos custos de produção, a logística e o real valorizado impulsionaram os preços externos da fruta.

\section{2. Índice de Orientação Regional para a União Europeia e para o Nafta}

Por meio do índice de orientação regional (IOR), pode-se verificar se as exportações estão orientadas para um país ou bloco específico. A Tabela 3 mostra o valor do IOR do mamão para a União Europeia. Assim, observa-se que os valores calculados foram maiores que um em todos os anos analisados, indicando que as exportações de mamão do Brasil estão orientadas para este bloco. De acordo com este resultado e analisando o modelo Constant Market Share, verificou-se que no primeiro período (1995/1998 a 1999/2001) o efeito destino das exportações foi negativo, portanto a União Europeia caracterizou-se como um mercado menos dinâmico. Já no segundo período (1999/2001 a 2002/2008), o efeito destino das exportações foi positivo, indicando que o bloco europeu se tornou mais dinâmico. 
Fernanda Aparecida Silva, Marília F. Maciel Gomes,

Daniel Arruda Coronel \& Marco Túlio M. Gomes

Tabela 3 - Índice de Orientação Regional (IOR) do mamão brasileiro, para a União Europeia, 1995 a 2008

\begin{tabular}{l|llllllllllllll}
\hline Anos & 1995 & 1996 & 1997 & 1998 & 1999 & 2000 & 2001 & 2002 & 2003 & 2004 & 2005 & 2006 & 2007 & 2008 \\
\hline IOR & 23,97 & 16,78 & 9,99 & 5,06 & 4,48 & 4,47 & 4,81 & 6,69 & 11,00 & 14,47 & 17,43 & 9,8 & 12,19 & 13,45 \\
\hline
\end{tabular}

Fonte: Elaborado pelos autores.

Observa-se, entretanto, que o índice de orientação regional apresentou grande oscilação durante o período analisado: maior valor em 1995 e menor valor em 2000. Além disso, é possível verificar que de 1997 a 2001, mesmo os valores sendo maiores que a unidade, o IOR se reduziu, voltando a crescer após 2002 e caindo novamente em 2006, já que o país exportou mais para o Canadá. Isso mostra que as exportações brasileiras de mamão estão alcançando novos mercados, constatação similar àquela obtida por Bratkowski e Ilha (2010), que analisaram a competitividade e orientação das exportações brasileiras de uva, melão e mamão, de 1997 a 2007.

Segundo dados da Secex (2010), em 2008, as exportações de mamão para a União Europeia cresceram $726 \%$ quando comparadas àquelas de 1995, enquanto as exportações extrabloco ${ }^{9}$ aumentaram $713 \%$.

No que se refere a estas barreiras impostas pela UE, sabe-se que até o ano de 2003 foram pouco rigorosas, exigindo apenas o Certificado Fitossanitário de Origem (CFO), que não requer nenhum tratamento específico para a fruta importada.

Porém, o mercado europeu está se tornando cada vez mais exigente quanto à importação de frutas. A União Europeia, visando a um maior controle de qualidade dos alimentos consumidos, exigiu, a partir de 2003, o selo EurepGap, criado em 1999, elaborado por um grupo de empresas varejistas (Euro Retailer Produce Working Group - Eurep). Esse selo visa a atender aos padrões das chamadas "boas práticas agrícolas" (Good Agricultural Practice - GAP), bastante difundido no mercado internacional

$\overline{9}$ Exportações brasileiras de mamão para o resto do mundo, excluindo a União Europeia. 
com ênfase na segurança do alimento, preservação do meio ambiente e preservação dos direitos dos trabalhadores (TODA FRUTA, 2010).

Como mostra a Tabela 4, o Índice de Orientação Regional apresentou, na maioria dos anos, valores menores que a unidade, excetuando 2000, 2001, 2002, 2007 e 2008. Mesmo o Nafta, sendo o terceiro maior importador de mamão nacional, em 2008, com US\$ 6,9 milhões, apresentou índice baixo, pois as exportações dessa fruta estão direcionadas para outros países ou blocos, como a União Europeia.

Tabela 4 - Índice de Orientação Regional (IOR) do mamão brasileiro para o Nafta, 1995 a 2008

\begin{tabular}{l|cccccccccccccc}
\hline Anos & 1995 & 1996 & 1997 & 1998 & 1999 & 2000 & 2001 & 2002 & 2003 & 2004 & 2005 & 2006 & 2007 & 2008 \\
\hline IOR & 0,023 & 0,03 & 0,18 & 0,4 & 0,97 & 1,16 & 1,24 & 1,15 & 0,94 & 0,614 & 0,577 & 0,57 & 1,032 & 1,058 \\
\hline
\end{tabular}

Fonte: Elaborado pelos autores.

A partir dos valores do IOR, nota-se que as exportações de mamão estão menos voltadas para a América do Norte em comparação com a União Europeia (Tabela 3). O ano de 1995 foi o que apresentou menor valor do índice, 0,023 , pelo fato de o Brasil exportar pequena quantidade para o Nafta.

O bloco que mais emitiu notificações para o mamão brasileiro entre 1995 e 2010 foi o Nafta, principalmente os Estados Unidos. O governo norteamericano exige que o mamão seja produzido em áreas livres de moscada-fruta, e que haja um certificado emitido pelo próprio governo norteamericano. Os Estados Unidos requerem ainda um selo, o APHIS (Serviço de Inspeção Sanitária de Animais e Vegetais), que permite a licença de importação, englobando regulamentos sanitários, fitossanitários e de saúde animal, sendo específico para cada fruta ou animal (VITTI ; BOTEON, 2008). 


\section{3. Índice de Cobertura}

Após analisar os efeitos que contribuíram para a evolução das exportações brasileiras de mamão entre 1995 e 2008 e se suas exportações estão orientadas para os blocos Nafta ou União Europeia, torna-se relevante identificar as principais barreiras sanitárias, fitossanitárias e técnicas impostas pelos maiores importadores de mamão. Para o cálculo do índice de cobertura, foram consideradas somente as notificações diretamente relacionadas com restrições às exportações da fruta, ou seja, as notificações regulares.

A Tabela 5 mostra o número de notificações regulares emitidas pelos principais importadores de mamão nacional, no período de 1995 a 2008, para os códigos 08, 0807 e 080720, classificados segundo a Organização Mundial de Comércio.

Tabela 5 - Número de Notificações (TBT e SPS) emitidas pelos importadores de mamão, entre 1995 e 2008, para os códigos 08,0807 e 080720

\begin{tabular}{|c|c|c|c|c|c|c|}
\hline \multirow[b]{3}{*}{ Ano } & \multicolumn{6}{|c|}{ Notificações } \\
\hline & \multicolumn{3}{|c|}{ TBT } & \multicolumn{3}{|c|}{ SPS } \\
\hline & União Europeia & Nafta & Brasil & União Europeia & Nafta & Brasil \\
\hline 1995 & 0 & 3 & 0 & 1 & 17 & 0 \\
\hline 1996 & 4 & 4 & 0 & 1 & 5 & 1 \\
\hline 1997 & 0 & 0 & 0 & 3 & 5 & 6 \\
\hline 1998 & 0 & 1 & 0 & 2 & 4 & 0 \\
\hline 1999 & 1 & 3 & 0 & 0 & 4 & 0 \\
\hline 2000 & 0 & 3 & 0 & 0 & 10 & 0 \\
\hline 2001 & 0 & 0 & 0 & 3 & 12 & 0 \\
\hline 2002 & 3 & 0 & 0 & 1 & 11 & 3 \\
\hline 2003 & 2 & 0 & 8 & 8 & 9 & 3 \\
\hline 2004 & 0 & 0 & 0 & 6 & 7 & 0 \\
\hline 2005 & 0 & 3 & 0 & 2 & 7 & 0 \\
\hline 2006 & 0 & 4 & 4 & 5 & 10 & 15 \\
\hline 2007 & 0 & 7 & 0 & 11 & 13 & 12 \\
\hline 2008 & 0 & 0 & 0 & 0 & 16 & 15 \\
\hline TOTAL & 10 & 28 & 12 & 43 & 130 & 55 \\
\hline
\end{tabular}

Fonte: Elaborado pelos autores de acordo com dados da OMC (2011). 
Como mostrado na Tabela 5, o bloco que mais emitiu notificações para o mamão brasileiro foi o Nafta, totalizando 28 TBTs e 130 SPS, o correspondente a $73,68 \%$ e $75,14 \%$, respectivamente. Já no caso da União Europeia, observa-se que o bloco lançou menos notificações que o Nafta, sendo responsável por $26,32 \%$ das TBTs e $24,86 \%$ das SPSs. Tais medidas justificam a menor orientação das exportações do mamão brasileiro para o Nafta em comparação com a União Europeia, pela imposição de maior número de barreiras sanitárias, fitossanitárias e técnicas.

Os valores obtidos para o Índice de Cobertura para o mamão são mostrados na Tabela 6, que indica o percentual do total das exportações que sofreram notificações.

Tabela 6 - Índice de Cobertura para o mamão brasileiro exportado para o Nafta e União Europeia, 1995 a 2008

\begin{tabular}{c|cc}
\hline Ano & União Europeia & Nafta \\
\hline 1995 & 1,35 & 5,13 \\
1996 & 3,12 & 11,87 \\
1997 & 2,41 & 9,16 \\
1998 & 3,48 & 13,20 \\
1999 & 5,83 & 22,16 \\
2000 & 4,08 & 15,51 \\
2001 & 6,95 & 26,40 \\
2002 & 13,58 & 51,59 \\
2003 & 18,39 & 69,88 \\
2004 & 10,18 & 38,69 \\
2005 & 12,74 & 48,39 \\
2006 & 12,36 & 46,95 \\
2007 & 14,65 & 55,67 \\
2008 & 2,50 & 9,51 \\
\hline
\end{tabular}

Fonte: Resultados da Pesquisa. 
Por meio desse índice, pode-se constatar que as exportações de mamão para o Nafta e União Europeia foram afetadas por restrições técnicas, sanitárias ou fitossanitárias, uma vez que o seu valor foi maior que zero ( IC > 0) em todo o período. O Nafta mostrou-se bem mais restritivo quanto à importação da fruta brasileira, apresentando elevados graus de proteção. Em 2003, foi observado o seu maior valor, 69,88\%, indicando que $69,88 \%$ das exportações de mamão nacional para este bloco sofreram algum tipo de notificação.

Verificou-se que em toda a série analisada o valor do IC para o Nafta foi maior que o valor do índice para a União Europeia, confirmando, portanto, que o bloco norte-americano emitiu um número maior de notificações ao mamão brasileiro em relação ao bloco europeu.

Comparando esse índice com o comportamento das exportações de mamão no mesmo período em questão, observa-se uma incoerência. As taxas de crescimento anuais médias das exportações dessa fruta para o Nafta e União Europeia foram de $29,18 \%$ e $18,54 \%$, respectivamente, ou seja, mesmo o IC sendo elevado para o bloco norte-americano, não houve queda na exportação de mamão para este destino. Portanto, outros fatores podem ter contribuído para o aumento das exportações da fruta, como apresentado no modelo Constant Market Share no período I (1995/ 1998 a 1999/2001), em que o efeito competitividade foi o que mais colaborou para o bom desempenho das exportações brasileiras de mamão, enquanto no período II (1999/2001 a 2002/2008), o maior responsável foi o crescimento do comércio mundial.

Além disso, o aumento das exportações brasileiras da fruta pode ter sido ocasionado pelas próprias notificações aos acordos SPS e TBT, uma vez que se trata de um meio transparente de divulgação de informações sobre as exigências do comércio mundial. Diante das informações contidas nas notificações, os exportadores brasileiros de mamão podem se adaptar e se enquadrar nas exigências impostas pelos importadores.

O índice de cobertura apresentou valores elevados para o Nafta, mostrando que grande parte das exportações de mamão brasileiro 
sofreram notificações, contudo, ao considerar as elevadas taxas de crescimento anuais médias das exportações para este bloco $(18,54 \%)$, observa-se que o Brasil tem conseguido adequar-se às barreiras técnicas e fitossanitárias exigidas pelos norte-americanos. Entretanto, as exportações de mamão nacional têm perdido competitividade, que pode estar associada, principalmente, à elevação nos custos de produção e logística, uma vez que o efeito competitividade foi negativo no período II (Tabela 2).

Segundo Passioni et al. (2006), outros fatores dificultam as exportações brasileiras de mamão. Ao analisarem os principais obstáculos das exportações brasileiras de banana, citrus, manga, mamão, melão e uva, informações obtidas por meio de questionários aplicados em 19 empresas, responsáveis por $46 \%$ do total exportado de frutas em 2005, constataram que houve diminuição dos entraves estabelecidos por outros países à exportação brasileira e que os custos de logística e a política cambial afetaram mais o desempenho das empresas exportadoras de frutas.

Entretanto, alguns autores, como Sousa et al. (2007), observaram que as medidas técnicas e fitossanitárias impostas sobre as exportações brasileiras de melão constituem de fato uma barreira ao comércio, visto que resultaram em elevados custos às empresas nacionais exportadoras da fruta.

\section{Conclusão}

O mercado internacional de frutas frescas apresentou grande dinamismo nos últimos 15 anos, crescendo cerca de $40 \%$ de 1995 a 2008 . No caso específico de mamão, a mesma dinâmica de crescimento foi observada. Verificou-se um aumento significativo das exportações brasileiras dessa fruta, da ordem de 568,41\%, no mesmo período referenciado.

Em face deste dinamismo, buscou-se neste trabalho analisar os fatores que contribuíram para o aumento das exportações brasileiras de mamão, 
avaliando para quais blocos elas foram orientadas. O período de análise foi de 1995 a 2008.

O efeito que mais contribuiu para o bom desempenho das exportações brasileiras de mamão, no período I (1995/1998 a 1999/2001), foi o efeito competitividade, impulsionado pela estabilidade da economia, desvalorização cambial, variáveis internas e programas do governo. Já no período II, o crescimento do comércio mundial foi o maior responsável pela variação nas exportações, seguido pelo efeito destino das exportações. Nesse mesmo período, a competitividade foi negativa, o que pode ser explicado pelo aumento do preço da fruta a partir de 2004, em razão da elevação dos seus custos, aumento nos custos logísticos e o real valorizado. No segundo período, portanto, a exportação de mamão tornouse mais dependente do dinamismo do mercado internacional comparativamente ao destino das exportações e à competitividade, dificultando, com isso, a atuação de políticas públicas.

A análise do Índice de Orientação Regional indicou que as exportações de mamão estão mais orientadas para a União Europeia do que para o Nafta, já que na maioria dos anos o valor do índice foi menor que um para os países da América do Norte. Entretanto, em alguns anos da série, os valores do índice mostraram que o Brasil vem alcançando novos mercados para o produto. Ademais, as maiores barreiras sanitárias e fitossanitárias impostas pelo Nafta podem explicar o fato de as exportações da fruta estarem orientadas para a União Europeia.

Em relação ao Índice de Cobertura, observou-se que as exportações de mamão para o Nafta e União Europeia foram afetadas por restrições técnicas, sanitárias ou fitossanitárias, pois o valor do IC foi maior que zero em todo o período. Verificou-se que o valor do índice para o Nafta foi maior que o valor para a União Europeia, confirmando que o bloco norte-americano emitiu um número maior de notificações ao mamão brasileiro em relação ao bloco europeu. Além disso, mesmo com o IC sendo elevado para o Nafta, não houve redução das exportações da fruta para o bloco. 
Conclui-se que mesmo que o Brasil tenha se destacado no comércio internacional de mamão, algumas medidas devem ser implementadas visando a ampliar sua competitividade, medidas essas voltadas para a valorização do produto, incentivo à produção e pesquisa, visando a a atender às novas exigências requeridas pelo mercado consumidor. A adoção de certificação, como, por exemplo, a exigência dos principais blocos importadores, quando não cumprida, pode levar à suspensão das exportações brasileiras de mamão. Essa ocorrência traria grandes prejuízos às empresas e produtores, resultando em redução na participação no cenário mundial.

\section{Referências}

BAIER, S. L.; BERGSTRAND, J. H. Do free trade agreements actually increase members international trade? Journal of International Economics. Vol. 71, 2007, pp. $72-95$

BALASSA, B. Trade Liberazition and Revealed Comparative Advantage. The Manchester School of Economic and Social Studies, 1965.

BANCO MUNDIAL. World Integrated Trade Solution. Disponível em < wits.worldbank.org> Acesso em: maio de 2011.

BARRAL, W. Protecionismo e neoprotecionismo no comércio internacional. In: O Brasil e o Protecionismo. São Paulo: Aduaneiras, 2002. 269 p. cap. 1, p.13-38.

BELLONIA, C. C. P. Barreiras Não-Tarifárias: Quantificação dos Efeitos sobre as Exportações de Carnes do Brasil. 2005, 75 f. Monografia (Ciências Econômicas). Universidade Federal de Viçosa, Viçosa, 2006. 
BRAZILIAN FRUIT - Programa de Promoção das Exportações das Frutas Brasileiras e Derivados. Disponível em: $<$ www.brazilianfruit.org.br>. Acesso em: 7 de maio de 2010.

CARRÉRE, C. Revisiting the effects of regional trade agreements on trade ûows with proper speciûcation of the gravity model. European Economic Review vol. 50, 2006, pp. 223-247.

CARVALHO, Fátima Marília A. de (1995). O comportamento das exportações brasileiras e a dinâmica do complexo agroindustrial Piracicaba ESALQ. (Tese de Doutorado).

CARVALHO, M. A. de; SILVA, C. R. L. Economia Internacional. São Paulo: Saraiva, 2000.

CENTRE D'ESTUDES PROSPECTIVE ET D'INFORMATIONS INTERNATIONALES - CEPII. Distances Disponível em: <http:// www.cepii.fr/francgraph/bdd/distances.htm> Acesso em: maio de 2011.

CORONEL, D. A. Fontes de crescimento e orientação regional das exportações brasileiras do complexo soja. Dissertação (Mestrado em Agronegócios) - Programa de Pós-Graduação em Agronegócios, Centro de Estudos e Pesquisas em Agronegócios, Universidade Federal do Rio Grande do Sul, Porto Alegre, 2008.

CORONEL, D. A. ; MACHADO, J A. ;CARVALHO, F. M. A. de. Análise da competitividade das exportações do complexo soja brasileiro de 1995 a 2006: uma abordagem de market-share. Revista de Economia Contemporânea, v. 13, p. 281-308, 2009.

FAO - FOOD AND AGRICULTURE ORGANIZATION OF THE UNITED NATIONS. Disponível em: < www.fao.org >. Acesso em: 16 de abril de 2010. 
Guimarães, M. C. O Mercosul e o desempenho do comércio intraindústria do setor brasileiro de papel e celulose. Dissertação (Mestrado em Economia Aplicada) - Programa de Pós-Graduação em Economia Aplicada - Universidade Federal de Viçosa, 2007.

IBGE - Instituto Brasileiro de Geografia e Estatística. Disponível em: <www.ibge.gov.br>. Acesso em: 24 de abril de 2010.

IBRAF - Instituto Brasileiro de Frutas. Disponível em: $<$ www.ibraf.org.br $>$. Acesso em 4 de maio de 2010.

KRUGMAN, P.R; OBSTFELD, M. Economia Internacional - teoria e política. São Paulo: MAKRON Books, 2005. 807p.

LEAMER, E. E; STERN, R. M. Quantitative international economics. Chicago: Allyn and Bacon, 1970.

MAPA - Ministério da Agricultura e Pecuária. Disponível em: $<$ www.agricultura.gov.br>. Acesso em: 26 de abril de 2010.

MINISTÉRIO DO DESENVOLIMENTO INDÚSTRIA E COMÉRCIO EXTERIOR (MIDIC). Secretaria de Comércio Exterior (SECEX), 2008. Disponível em: <www.mdic.gov.br/sitio/secex/secex/informativo>. Acesso em: 22 de abril, 2010.

PASSONI, A. C.; NEVES, M. C. M.; RODRIGUES, B. B.; BOTEON, M. Análise dos Principais Entraves nas Exportações de Frutas Brasileiras. Anais do XLIV Congresso Brasileiro de Economia e Sociologia Rural. Fortaleza, 23 a 27 de julho de 2006.

PORTER, M.E. A vantagem competitiva das nações. Rio de Janeiro: Campus, 1993.

PORTER, M.E. On competition. Harvard: The Harvard business review book series, 1999 . 
Fernanda Aparecida Silva, Marília F. Maciel Gomes,

Daniel Arruda Coronel \& Marco Túlio M. Gomes

PORTER, M.E. The competitive of nations advantage of nations. Harvard: The Harvard business review book series, 1998.

RICARDO, D. The principles of political economy and taxation. New York: The Modern Library, 1967.

RICHARDSON, J. D. Constant - Market - Shares analysis of export growth. Journal of International Economics, v.1, p. 227 - 239, Jul. 1971.

RUBIN, L. S., ILHA, A. S., WAQUIL, P. D. O comércio potencial brasileiro de carne bovina no contexto de integração regional. Revista de Economia e Sociologia Rural Piracicaba, SP, v.46, n.4, p.10671094, 2008.

SALVATORE, D. Economia internacional. Rio de Janeiro: Livros Técnicos Científicos (LTC), 1999.

SMITH, A. The wealth of nations. New York: The Modern Library, 1937.

SOUSA, E. P.; CAMPOS, A. C.; LIMA, J. E. Análise de Intervenção Aplicada as Exportações Brasileiras de Melão. Anais do XLV Congresso Brasileiro de Economia e Sociologia Rural. Londrina, julho de 2007.

STALDER, S.H.G. Análise da participação do Brasil no mercado internacional de açúcar. Piracicaba, 1997. 121p. Dissertação (MS) Escola Superior de Agricultura "Luiz de Queiroz", Universidade de São Paulo.

THORSTENSEN, V. Organização Mundial do Comércio: As regras do comércio internacional e a nova rodada de negociações multilaterais. 2a ed. São Paulo: Aduaneiras, 2003. 517 p. 
VitTi, A. ; MElo, A. L. F.; BOtEOn, M. Potencialidade e oportunidades para a fruticultura brasileira no mercado internacional. Artigo da $47^{\circ}$ Congresso da Sociedade Brasileira de Economia e Sociologia Rural - SOBER Disponível em: $<$ www.cepea.esalq.usp.br/pdf/AlineVitti.pdf $>$ Acesso em 05 dez 2010.

WAQUIL, P. D., et al.. Vantagens comparativas reveladas e orientação regional das exportações agrícolas brasileiras para a União Europeia. Revista de economia e agronegócio. Viçosa: UFV, v.2, n.2, p.137-159, 2004.

WILLIANSOM, J. A economia aberta e a economia mundial - um texto de economia internacional 5. ed. São Paulo: Editora Campus, 1997.

YEATS, Alexander. Does Mercosur's Trade performance rice concerns about the effects of regional trade arrangements? Policy, Planning and Research Working Paper n. 1729, Washington: Word Banck, fev. 1997. 